\title{
The Disorder of World Thought
}

\author{
MICHAEL A. KELLEY \\ GARY D. WEKKIN \\ University of Central Arkansas
}

There has emerged in recent years a cascade of criticism aimed at the alleged obsolescence of the nation-state system which currently orders global politics, and the inadequacies of "mainstream literature and teaching about international studies (which) do not focus sufficiently upon global problems or long-range strategies for dealing with them" (Weiss, 1974: 22). According to this view, orthodox, empirical international studies train their focus on the state and its traditional "high politics" concerns of war and peace to the exclusion of other weighty concerns such as environmental deterioration, poverty, social injustice, and individual alienation. Nor are orthodox empirical studies likely to discover solutions to these problems, or even that of war, because these are seemingly products of the very nation-state system which the international studies discipline, in its empirically conservative concern with state interactions, helps to perpetuate. A new normative order embracing the goal of world community is said to be needed if we are to survive these supposed dysfunctions of the nation-state system, and many advocates of this approach have set themselves the task of revising the international studies discipline to include discussion of all relevant problems, values, potential forces for change, and strategies for molding the future.

Foremost among those stating these criticisms are those scholars as sociated with the New York based Institute of World Order and its World Order Modeling Project, a collaborative effort by academic teams from eight nations to design a set of relevant utopias (defined as positive models of world order accompanied by transition strategies) that could be realized by the 1990's (Falk, 1975: 7). Utopian critiques and models published under the auspices of WOMP (now known as the World Policy Institute) include Richard A. Falk's A Study of Future Worlds (1975), Johan Galtung's The True Worlds (1980), Rajni Kothari's Footsteps into the Future (1974), Ali A. Mazrui's A World Federation of Cultures (1976), and Saul Mendlovitz's On the Creation of a Just World Order (1975). Other prolific contributors to the stillgrowing utopian literature include World Order educators Louis Rene Beres (1975, 1981), Lincoln P. Bloomfield (1975), Thomas G. Weiss (1974, 1974a), and Michael Washburn $(1975,1976)$.

Having thrown down the gauntlet to mainstream, empirical international studies, it is fair that these critics should stand the return of the compliment -- a critique of the scholarship of World Order modellers and educators (hereafter referred to as World Order utopians). Others, specifically Hedley Bull (1977) and Stanley Hoffman (1981), already have offered critiques of some of the works cited above, but still the litera ture and outlook of this utopian lot continue to enjoy widespread currency. Consequently more analysis of the general intellectual tendencies of World Order utopianism may be valuable for members of the international studies and political science disciplines. Generalization about the main themes of World Order utopianism of course necessitates both selective quotation of the literature and a selective focus, but those familiar with the litera ture will concur that one finds considerable repetition of themes in Falk's This Endangered Planet (1972), A Study of Future Worlds (1975), and A Global Approach to National Policy (1975b), or considerable similarity of viewpoint in the works of Kothari (1974), Mazrui (1976), and other Third World-oriented writers. 


\section{World Order Utopianism}

The World Order utopians contend that the international studies discipline's traditional focus on the nation-state and its central concerns of war, peace, and status has blinded us to other, less conspicuous but equally threatening problems such as ecological breakdown, overpopulation, poverty, social injustice, and human alienation. In the not very distant past, World Order utopians note, all of these concerns fell within the purview of national, provincial, or local government responsibility. "Food, employment, commerce, currency, coastal waters, health, clean air and fuel -- these represented the mundane tasks of domestic government..." (Bloomfield 1975: 44). But now, they argue, the competitive nature of the interstate system and the fabulous growth of technology have combined to cause the best and worst of human activities, whether travel, satellite broadcasting, MNCs, oil spills, or atmospheric nuclear tests, to overflow national boundaries. Formerly domestic concerns have assumed global proportions and become transnational issues, and yet there is no equivalent supranational authority capable of dealing with such matters. The vast bulk of governmental machinery available is either national or subnational, and has no authority to formulate solutions to transnational problems such as acid rains or refugee movements. Indeed, it is the nation-states and their statist imperatives which are said to be the chief cause of such problems:

States compete with one another for power, wealth and prestige, and jealously guard their sovereign prerogatives. This competitive pattern generates waste, conflict, and distrust...(Falk, 1972:2).

Consequently, World Order utopians advocate replacement of the traditional assumptions, foci, methods, and goals of international studies with 'new' assumptions that galvanize, 'new' foci that are problem-relevant, and 'new' aims that are prescriptive and idealistic. Many differences in approach are abstracted in a tabular comparison of World Order utopianism and traditional international studies which has appeared in several works of the World Order utopians (see Chart 1). But it is necessary to understand World Order utopianism through the eyes of its principal contributors.

\section{A Priori Assumptions, Foci, and Prescriptions}

As the eleventh comparison in Chart 1 indicates, the galvanizing assumption of the World Order utopians is that human survival on this planet is endangered, thus necessitating a dramatic restructuring of human activity on a global scale. Authors such as Galtung, Beres, Falk, Kothari, Weiss, and Washburn all share an apocalyptic vision of the future exemplified by the Bloomfield's (1975: 46) statement that:

\footnotetext{
food shortages already have killed more than the two nuclear bombings in 1945 and, in the future, could be even more genocidal. Uncontrolled assaults on the earth's ozone envelope...could give skin cancer to thousands. Undrinkable water can poison cities. Mass unemployment can undermine family life. And unchecked population growth..." is the principal and most compelling threat to the survival of the species".
}

All advocate World Order reform because they view these crises as beyond the capacity of nation-states to manage, if not in fact the products of the competitive state system. All therefore advocate at minimum, as Falk (1975: 2) explains below, the augmenting of the state system with higher forms of human organization, usually of a functional or confederal nature; and some even argue the need for supranational forms that transcend state sovereignty. 


\section{Chart 1}

\section{Traditional}

1. Geopolitical focus is the nation-state system

2. Problems are seen as discrete issues.

3. Analysis is presumed value-free.

4. Priority time dimension is the past and present. present as instructive to it.

5. Ultimate analytical objective is description and prediction. tion.

6. Ultimate operational objective is awareness for problem management.

7. Primary actors are seen as nationstates and governmental elites.

8. Policy goals are viewed mainly in terms of the maximization of national power and wealth.

9. Power is considered primarily with reference to military and economic force.

10. Large-scale violence is ordinarily deemed an acceptable means to implement policy.

11. Human survival is assumed.

\section{World Order Approach}

1. Geopolitical focus is the global community.

2. Problems are seen as interrelated structural or systemic issues.

3. Analysis is presumed valueoriented.

4. Priority time dimension is the future, with the past and

5. Ultimate analytical objective is prediction and prescrip-

6. Ultimate operational objective is participation for basic progressive change, with emphasis upon individual involvement.

7. Primary actors are seen as ranging from individuals to transnational organizations and supranational institutions.

8. Policy goals are viewed mainly in terms of the maximization of human well-being and fulfillment.

9. Power is considered primarily with reference to moral suasion and the force of people united in nonviolent action.

10. Large-scale violence is deemed an unacceptable means to implement policy.

11. Human survival is assumed to be problematic. 


\title{
Michael A. Kelly and Gary D. Wekkın
}

A world system composed of sovereign states cannot deal effectively or equitably with the problems facing humankind. Some form of global integration is needed to facilitate the shaping of policy and the sharing of resources (Falk, 1975:2).

The focus of World Order utopians reflects their underlying assumption that human survival within the context of the present state system is problematic. Repelled by "what is and will be," they focus much of their efforts on dramatizing the imminent threats to humanity's continued existence Galtung, (1980: 18) specifies war, inequity in need satisfaction, and the depletion and pollution of nature as reasons why "humankind is in trouble." Falk concurs that:

The planet is too crowded and is getting more so.

The war system is too destructive, risky, and costly...

An increasingly large number of people live at or below the level of subsistence.

Pressure on the basic ecosystem of the planet is serious and growing...

Governing groups in many societies are repressing their own people...

Technologies are not adequately managed...(1975a: 221-22)

Falk goes on to set down the ideal goals of the alternative world order change he feels the above concerns necessitate:

\begin{abstract}
On the basis of these concerns we seek by the end of the century a world system that: achieves and moves beyond the norm of zero population growth; moves toward dismantling the war system, including putting into effect a plan for drastic disarmament; moves toward a world economic system in which each individual is assured the right to minimum requirements of body, mind, and spirit and in which food, clothing, housing, education, health, and work are regarded as collective as well as personal responsibilities; moves toward an integrated and coherent system of dynamic equilibrium so far as human impacts on the biosphere are concerned; achieves and moves beyond a minimum bioethical code based on human survival, planetary habitability, and species diversity; moves toward a conservation policy that is sensitive to the life chances of future human generations and protective of natural wonders and species.../and/ achieves a system of global oversight on the side effects of technological innovation (1975a: 222).
\end{abstract}

Most World Order utopians share the same assumption of impending cataclysm and take seriously the question of human and planetary survival; consequently, most of them also share most of Falk's ideal goals, within varying degrees. But here the similarity of World Order utopian thought ends. Divergence of thought begins with prescription, with the question of how best to realize these goals and avert the crises besetting the present state-dominated order.

Falk, for instance, develops a model world order in which a central guidance bureaucracy called the "World Polity Association" is the evolved result of a buildup of functional agencies and regional organizations. Shunning the formal shift of authority from states to global actor so often mandated in world government solutions, Falk assumes that development of his central guidance system (complete with World Assembly, executive council, cabinet, and functional-specific age bureaucracy) will be expedited by the steady growth of regional organizations, functional organizations, the UN, and transnational actors between the 1970's and the year 2000, while nation-states' capabilities stagnate and dwindle by half.

Galtung envisions a world of many (e.g., 1500) small, diverse societies organized along the lines of Chinese people's communes, Tanzanian ujamaas, Gandhian sarvodaya villages, kibbutzim, hippie colonies, autonomous cities, and Dahomey-sized states. Arguing that 'smallness' facilitates democratic decisionmaking and prevents hegemonism, Galtung would break up the largest and strongest nation-states. Yet, he also ad mits the necessity of a vague "central world authority for world planning and world execution of essentials....there must be somewhere some central authority...for such matters as world food distribution, world 
employment, world ecological balance..." and so forth (1980: 92-3). Mazrui envisions an even more vaguely defined world federation of cultures (of political, economic, and intellectual aspect) based on three principles: recognition of global cultural interdependence; parity of esteem for each culture (to prevent dominance); and promotion at a federal level of "cultural fusion" to develop a shared culture binding the constituent cultures together (1976: 70-77). Kothari prefers a world federation of 20 to 25 great powers and countervailing integrated actors (e.g., regional organizations, Third World associations), without a strong federal authority at the apex (1974: 12-14). Others, such as Beres and Washburn and Wehr, do not offer any prescriptive models in their education-oriented works, but exhort other scholars to do so, and state their focus also to be the future even though they have no vision themselves of what the future could and should look like.

Unlike more traditional approaches to the subject, a World Order orientation does not require scholars to tie their inquiries to what exists today.... It thereby encourages scholars to range widely, freely, and imaginatively in their studies (Beres, 1981: 18).

Correspondingly, World Order utopian scholarship concerning the problem of transition to a "preferred world" is an eclectic potpourri, perhaps reflecting the diversity of world order prescriptions, or the opaque quality or absence of prescribed models in some authors' works, or a certain desperation born of the utopians' assumption of impending cataclysm. The only common ground seems to be implicit recognition of the necessity of elite support for world order change to be feasible. Beyond this, World Order utopians disagree with one another on what constitutes a vital elite, how great is the potential of various elites for contribution to change, and how to recruit and develop elite support.

Washburn and Wehr, for instance, stress that "the university has a central role to play in the creative transformation of society" (1976: 6), and devote most of their book to the tasks of raising the consciousness of their fellow academics and formulating World Order education curricula. Kothari, however, minimizes education's likely contribution to change ("what most people mean by education is economically costly, politically counterproductive, and culturally disruptive..."), as well as that of labor, youth, and other social movements (1974: 123, 131-32). He believes it is up to the Third World countries' national elites "to unsettle the existing system of world power," and exhorts third world states to coordinate their activity, pool their resources, and mobilize friendly international civil servants in order to effect fundamental change in the character of international politics.

Galtung believes the world might be made over through the efforts of a world citizens' movement adhering to a new, selfless, politically conscious model of human behavior ("By means of citizens' initiatives a fight against structural violence is launched, experience is gained, autonomy is realized, peace is created" -- 1980: 419). He cites Daniel Ellsburg as a possible model of behavior for the members of such a movement. Change would grow from the grassroots up, apparently spreading its influence among critical bureaucratic elites as they are recruited from the changeinfected grassroots. Ultimately, institutions would be populated by "MegaDans" -literally, a million Daniel Ellsburg types in foreign offices, defense ministries, and MNC headquarters all over the world (1980: 417-19).

Falk, unlike Kothari, puts great faith in the ability of current social movements and "Education and related strategies of persuasion" to help mobilize or even create new social and political forces committed to World Order change (1975: 277). In "Toward a New World Order" (1975: 278ff), he elucidates four basic transition steps. First, "identify actors and social forces receptive to world order change", such as the progressive governments of Sweden, Canada, and Norway, progressive cities such as New York which might secede from their benighted hinterlands, and social movements for labor, women, and minority rights whose values are in resonance 


\section{Michael A. Kelly and Gary D. Weikin}

with world order change and thus might be recruited to the cause. Second, "mobilize receptive actors and social forces to support transition to a preferred world organized around WOMP values." Here Falk suggests introduction of the above actors into Amnesty International petition campaigns, campaigns of divestiture aimed at repressive regimes, and other activist movements as vehicles for the socially responsible to spread preferred values throughout the international system. Third, "create a climate of public support for global reform." Consciousness-raising through universal World Order education courses, dissemination of the reports of progressive study groups such as SIPRI and the Club of Rome, and the encouragement of "multinational corporate globalism" and the "free flow ethos" are suggested. Finally, "identify potential areas of transnational cooperation." Here Falk suggests that the UN might be given independent regulatory roles with respect to air piracy, satellite broadcasting, narcotic enforcement, space ownership, and other transnational issues, thus prompting more cooperative approaches to international problems.

In short, the foci of World Order utopianism include dramatization of threats to survival, prescriptive models of the future, and prescription of transition strategies, but largely eschew the nation-states which are still the most critical actors in the present system. Virtually the only respect in which most World Order utopians mention the state actors is to blame them -- especially the powerful 'Center countries' of the Northern hemisphere -- for most of the problems which threaten human survival, and to insist that they adopt policies of self-abnegation:

In the Center countries nothing should be spared to demoralize and weaken those who might possibly make use of methods of direct violence to maintain the pattern of structural violence, between countries as well as within countries (Galtung, 1980: 424).

\section{Methodology}

As the third and fifth comparisons in Chart 1 indicate, World Order utopians presume analysis to be value-oriented, and the ultimate objective of analysis to be prediction and prescription, not just description and explanation. World Order utopians claim to attempt a coupling of normative theory and scientific inquiry, in keeping with Easton's (1969) call for a 'post-behavioral revolution.' As Galtung explains World Order utopian inquiry,

\footnotetext{
Methodologically, I am left with no choice. To peer into the future with the methods of empirical science means extrapolation, and prediction based on extrapolation today points to catastrophe. It is completely rational today to predict both nuclear war and worldwide famine. Hence the world situation demands that we do more than extrapolate. Only explicit values and theories about their realization can yield a different perspective. There is no alternative to trying to turn our course in a new direction. More empirical analysis will not do. We know more or less what we need to know about the empirical world. It is potential reality and its realization that we are dismally ignorant of in our excessive empiricism (1980: 30).
}

Thus, in a world seemingly careening toward cataclysm, values become as epistemologically important as empirical data; and theories of world politics, to be meaningful and useful for an endangered world, must contain the seeds of both. Galtung depicts the World Order method of inquiry as a "triangle" of data, values, and theories sequentially intertwined with the tasks of understanding, criticizing, and constructing, respectively (1980: 30). Falk claims to share this concern for blending scientific method and norm, stating his objective to be

...to encourage disciplined inquiry into the future of international relations from an avowed and explicitly normative perspective.... [ $1 \mathrm{am}]$ against a value-neutral approach.... At the same time, I have tried to understand and present the state system as it operates and to avoid...wishful thinking...(1975: xxix). 
Yet, despite all the promises of a bright new synthesis, and despite the employment of scientific language and raising of epistemological issues, World Order literature exhibits a strong undercurrent of dissatisfaction with the empirical mode of inquiry. Mendlovitz complains that

\begin{abstract}
There is initially the bias in the social sciences against work that explicitly utilizes preferences and values as a way of defining problems to be investigated, and as a standard to be used for what will be considered an adequate solution to the problems. Research that deviates from the confines of a perspective that is viewed by its adherents as empirical and scientific, is either dismissed as being ideological or as being an exercise in wishful thinking...the same tradition's narrow sense of realism and empiricism operates quite decisively to inhibit futuristic thinking and orientation (1975: vii).
\end{abstract}

Other leading World Order theorists have shown where their proclivities lie on the normative-empirical continuum by urging scholars to "give up the moralistic pretension of the liberal pedagogy that they are only part of the teaching process" (Falk, 1975a: 219), and adopt the role of "social creator" (Weiss, 1974: 23) or "agent of historical change" (Kothari, 1974: 128-31). Given such exhortatory, socializing statements by such elite scholars, it comes as no surprise that exhortatory, consciousness-raising works have become standard fare, and that even some World Order utopians complain that much of the literature produced by their colleagues is unscientific. Beres and Targ, who collected and edited a volume of essays on World Order modelling procedures admit that "social thought concerning alternative world futures has placed little or no emphasis on the essential methodological underpinnings of inquiry" (1975: xii). Indeed, in their own volume, "Some of the authors display an uncommon solicitude for the utility of works of art, science fiction, or metaphysical materials to stimulate the design enterprise, [as] a preoccupation with rigor might have an inhibiting effect on the minds of researchers" (1975: xxiii-xxiv). Mendlovitz admits that a similar proclivity for value-oriented research is characteristic of most of the eight World Order Modelling Project research groups. In his introduction to the volumes sponsored by WOMP, he notes that

It is probably fair to say that we discovered more methodological problems than we were able to solve to our satisfaction....In the end, most of the WOMP research groups chose to adop! the more traditional analytic, interpretative style of research, rather than the more methodologically sophisticated behavioral science approach. The reasons for this choice varied from outright rejection of the presumed conservative biases of strictly data-based methods to pragmatic considerations of limited time and resources (1975: xii).

\title{
A Scientific Critique
}

The raison d'etre for World Order utopian studies is the stated belief that empirical, state-centric international studies "do not focus sufficiently upon global problems or long-range strategies for dealing with them....traditional conceptions are becoming less effective and less relevant" (Weiss, 1974: 22). Now let us hold the World Order utopians to the same standards by which they have found international studies wanting. Do the World Order utopians themselves focus sufficiently and fruitfully on global problems and the construction of solutions to them? Do the alternative world orders they pose as solutions truly meet the criteria of "relevant utopias," in the sense that they are improvements upon the existing order and include feasible strategies for accomplishing transition? Are utopian World Order models more effective, more relevant conceptualizations of changing global politics than the state-centric or other models? Do their conceptualizations, their proposed prescriptions and transition strategies stand up to the test of empirical verification?

Our answer to all of these questions is negative. Generally speaking, World Order utopian scholarship and its claims cannot be validated, despite its alleged attempts to couple normative theory and scientific inquiry. To qualify as a scientific 


\section{Michael A. Kelly and Gary D. Wekkin}

body of knowledge, World Order scholarship first must establish a relevant methodology that is con scious of the benefits and requirements of intersubjectivity and is capable of organizing meaningful research, establishing cause, and generating policy-relevant prescriptions and transition strategies that would accomplish not just mere "change", but the realization of the modellers' specific desired outcomes. Second, World Order scholarship must display parsimonious conceptualizations that are operational and testable. Third, World Order utopian scholars must demonstrate that their perceptions and prescriptions can withstand empirical examination and research. The discussion that follows shows that the works presented above do not meet either their own criteria or the criteria of social science very well.

\section{Methodological Concerns}

Ahistoricism. The first methodological weakness of World Order utopianism is that its views on the necessity of leaving the present state system behind have spawned ahistoricism and devaluation of the intersubjectivity of knowledge. All that humankind has experienced and known cannot be eschewed as irrelevant simply because one's main focus is the future. Yet, many seem to believe that, as Galtung stated above, we already have enough empirical knowledge of what is, but lack sufficient knowledge of what might be, of how the disastrous portents of the present might be averted. Convinced that weapons of mass destruction, global maldistribution of wealth, and environmental breakdown, all necessitate creation of a new' 'global village' divorced from past mistakes and present trends, World Order utopians have rushed toward alternative futures at the expense of leaving behind relevant human experience and thought. This may be seen in the assumptions, focus, and prescriptions of World Order utopianism, which upon examination differ little from those of various already discredited international thinkers whom the World Order utopians appear unaware of.

The Kantian assumption of Galtung, Beres, the Bloomfields, and others that we ought to restructure our world system because we must do so if we are to avert impending (nuclear or ecological) doom is the same as that which motivated Borah, Dewey, Levinson, Shotwell, and other Idealists active in the 'Outlawry' movement, and to a lesser extent those Idealists in volved in the League of Nations movement (Levinson, 1921; Dewey, 1923; de Madariaga, 1929). A second World Order utopian assumption is similar to that which gave rise to the Legalists' pre-1914 attempts to prevent warfare through the buildup of international law; namely, the Benthamite belief that the public can be relied on to judge rightly and act accordingly on any question rationally presented to it (Fox, 1949: 68-70, Root, 1969: 3-6, 125-28). Falk has written that "The first need is to awaken the consciousness of men and women everywhere to the causes of their distress" (1972: 3). Galtung concurs that newly conscious individuals can initiate World Order change, and prescribes little other than consciouness raising. And the Bloomfields are convinced that the public already has judged rightly on the need for a new World Order:

But the average citizen all over the world strongly desires that his pressing problems be solved and that govermments get together if necessary to reach solutions.. he has long since made his commonsense choice in favor of the alternative notion of sovereignty as a liquid..(1975: 49).

Thus, the cornerstone of much World Order thinking (especially about transition) is still the ages-old utopian assumption that accomplishing change is a simple matter of attracting mass assent through rational persuasion, and not a political process involving diverse, contending interests. (Even were this assumption true, mass assent for world order change might prove an elusive goal, as data presented below indicates.) 
The focus of World Order studies, like that of the Idealists, similarly ignores historic and current interactions of nation-states in favor of the prescription of preferable supranational arrangements such as Galtung's world of small societies, Kothari's federation of regional or ganizations and states, Mazrui's federation of cultures, and Falk's World Polity Association. These "relevant utopias," and many of their corollary prescriptions, such as the widely-favored redistribution of resources from North to South (virtually all World Order utopians call for this), must surmount the same obstacle that has undone the League of Nations, the Abb'e de Saint-Pierre's Project for Perpetual Peace, Dante's De Monarchia, and every other utopian scheme of world order conceived by man thus far. They fail to recognize that, as Rousseau's critique of the Project for Perpetual Peace and Carr's The Twenty Years' Crisis both pointed out, any global scheme to achieve order (or to allocate power and wealth) will almost certainly be disturbed by dissatisfied revisionist forces, or, failing that, resisted by reluctant status quo forces. Will messianic Islamic fundamentalists, orthodox Zionist settlers, revolutionary Marxists, and imperialistic capitalists sublimate the imperatives of their respective dogmas to Mazrui's ideal of a harmonious federation of cultures? Will the hungry of the Third World share Falk's World Polity Association's concern to protect endangered species or prevent further pollution in the biosphere, if such would interfere with their own economic needs? Will western Canadian provinces which no longer wish to subsidize Quebec and the maritime provinces, or middle-class American tax-protestors who no longer wish to subsidize American welfare mothers, share their wealth unstintingly with distant, faceless, hopelessly numerous Third World masses? Will ambitious individuals of any stripe, anywhere, submit to Falk's proposed maximum income (1975: 360)? Will Galtung's 1500 small (and supposedly non- hegemonic) societies truly add up to a 'global village,' or might such weak entities regard one or a combination of their peers with fear or envy, thus creating the insecure state of nature which Hobbes and Morgenthau identify as the very root of hegemonism? As Rousseau concluded, politics are inevitable, even under world states and other utopias, for these would mean codified distributions of power and wealth which some will always fault.

Misuse of 'Models.' World Order utopian literature uses the term model pervasively, and often incorrectly. In the purest sense, a model should be rooted in reality, and not a device of artifice, for the term model (in its original and most accurate meaning) refers to the isomorphism between the elements of the model and the elements of that which it is a model of (Brodbeck 1959: 374-81). A model should be "a representation of reality" (Nachmias \& Nachmias 1981: 47), a heuristic device to which the real world is compared as data are gathered. (Williamson, Karp, Dolphin \& Gray 1982: 20). However, examination of the World Order models presented above reveals that most World Order modellers reject present or real condi tions in the formation of their preferred worlds. Indeed, Washburn (1975) and Wagar (1975) even hold that World Order models might derive from the fertile and speculative fields of art and science fiction.

Of course, it is true that many of the most useful models in political and international studies are suggestive precisely because they, too, are not truly representations of reality, but representations of some other familiar thing that may be used to organize the study of unfamiliar but real phenomena (e.g., game theory models of international politics derived from poker). The problem, then, with World Order utopian models is not the source of their derivation, but the fact that they cannot be either isomorphic or suggestive of that which does not yet exist. Therefore, they are not models. It is instructive to note that Isaak categorizes the construction of alternative futures by Kahn as "heuristic techniques.../that/ are alternatives to models but they can often be used in a complementary manner" (1981: 183-84). 
Causation. One of the most fundamental and critical flaws in World Order utopian thinking is the questionable attribution of cause. Determination of cause demands "a very high order of experimental elaboration" and must be "the culmination of a long process of hypothesis formation and testing" (Hoover, 1980: 86). Obviously, without first articulating and verifying hypotheses, World Orderists may not cast either the nation-state (Falk, 1975) or capitalism (Galtung, 1980) as the sources of evil in the world, or ascribe to their alternative world orders the certainty of peace and justice. World Order utopian disregard for empirical verification leaves the door wide open for alternative explanations and forecasts.

The assumption that the nation-state is the source of international injustice and war confuses correlation with causation. War and injustice are aspects of the past and present systems, but this does not necessarily mean one is the cause of the other, (MacIver, 1942: 91-2). In fact, the obverse of the causal claim linking nation and violence could be stated if one accepts Herz's thesis (1957) that the nation-state emerged as an answer to violence, personal insecurity, and injustice. Obviously, establishing the direction of the causal arrow here should properly be the culmination of a long process of hypothesis testing. This is particularly important when there are numerous potential alternative explanations for the exist ence of international conflict, such as economic imperialism (Lenin, 1916), racism (Fanon, 1963), "merchants of death" (Ziegler, 1981: 116), or in stinctive causes of aggression exemplified in the ethological works of Lorenz (1967), Storr (1968), and Ardrey's "territorial imperative" (1966).

The assumption that the developed countries deserve a greater share of the blame for world problems than the less developed countries further compounds the fallibility of the above attribution of cause. In their eagerness to assign responsibility for Third World poverty, instability, repression, and violence to the U.S. and other "imperialistic" Center countries, World Order utopians disregard that domestic forces in LDCs play a principal role in determining their own fates. Surely Indian social structure and culture bear some responsibility for conditions in that country, just as Japanese social structure and culture deserve much of the credit for Japan's successful development despite prolonged feudalism, late industrialization, lack of raw resources, overpopulation, total defeat, and occupation. African specialists have observed that the African nations themselves may be responsible for many of their own problems (Smiley, 1982), and Southeast Asian specialists agree that "Southeast Asia has had a dynamic history all its own," and extraregional influences have only been a part of this history, rather than having been its main source (Smail, 1961; Zacher \& Milne, 1974: xviii). Perhaps the worst form of imperialism we practice is to perceive everything that happens in the less developed countries as the result of our own domination, which is tantamount to denying Third World peoples a hand in the making of their own history.

Prescription. A related problem is that without clear determination of causation, it is difficult to generate solutions that are any more than vague statements of hope and resolve. MacIver points out that "inability to grapple with causation is the main obstacle" to knowledge of a higher order, or prescription.

\footnotetext{
For unless we can discern the causal nexus of things, we do not know the way they belong together or the way they are set apart, we do not know the nearer and more inclusive systems they constitute. We do not know their behavior or their properties or the routes they follow in changing their relationships. We are limited to description and insecure classification (1942: 77).
}

World Order utopians have journeyed well past the limits set for those who have not pinpointed causation. How can world federations or other supranational entities prevent structural violence, if the nation-state is not in fact the primary seed of violent conflict? Substituting the issue of social injustice for that of war, we might ask the 


\section{Tie Bisorder of World Order Thought}

same question: how would replacing the nation-state with higher forms alleviate social injustice, which history shows to have preceded the nation-state into existence? What good is redistributing wealth from North to South, if in fact unreformed, indigenous feudalism, tribalism, or caste systems prove greater obstacles to economic development and economic justice than is imperialism? Would not redistribution then impoverish many in both hemispheres, rather than achieving the desired equity? Physicians should not prescribe cures without first determining the cause of illness.

Having already made a Rousseauvian critique several specific World Order models (above, msp. 11), let us put aside the form and substance of World Order prescriptions and turn to the transition strategies which are an integral part of these prescriptions, according to Falk's definition of "relevant (i.e., attainable) utopias." Since Falk himself devotes more at tention to the transition problem than any other World Order utopian, let us examine his four basic transition steps (see above).

1. "Identify actors and social forces receptive to World Order change." Falk's argument that some governments (e.g., Sweden, Canada) might support world order change because their values are consonant with WOMP values is a subjective judgment which disregards, first, that even such "moral" governments are nonetheless bureaucratic organisms interested in their own survival, and second, that governments historically have tailored their moral postures to serve their particular nation interests, as Carr's essay on "The Harmony of Interests" (1964) illustrates. It is questionable, for instance, whether Canada in quest of its own identity, and historically resistant to national integration as well as continental integration, would favor global integration and accompanying distance of authority. It also is questionable whether Canadian norms are any more consonant with WOMP values than those of other nations. Domestically, the economic conditions of many Indians and Quebecois and the prejudice encountered by East Indian immigrants suggest that social injustice still exists in Canada; internationally, the Canadian government has refused to end the organized slaughter of baby fur seals, barred Taiwanese athletes from the Montreal Olympics just to secure trade advantages with China, and sold Candu reactors to India and Argentina, among other things. India, as forecast, used its Candu to build a bomb; the Argentine military government may follow.

2. "Mobilize receptive actors and social forces to support transition to a preferred world..." This strategy disregards that many labor unions and domestic reform movements (especially in the Center countries critical to change) are essentially conservative because of material orientation, or co-optation. Their goal is usually a bigger piece of the domestic pie. Is it realistic to expect them to support any value change which might reduce that pie (such as Falk's maximum income proposal), or redistribute part of it outside the domestic context? (Consider American labor's record on environmentalism when growth and jobs are at stake, the British Labour Party's desire to leave the EEC, or the French Socialists' stance on agricultural issues and on defense preparedness.)

3. "Create a public climate of support for global reform." Again, we are presented with ill-considered strategies. Falk's suggestion that "multinational corporate globalism" may serve as a transition tactic or alternate focus for human allegiance flies in the face of the possibility that the wars, poverty, social injustice, environmental despoliation, and human alienation Falk wishes to alleviate are caused not so much by the nation-state system as by corporate capitalism. How could the economic determinists in the Marxist world, who view the economic structure as the infrastructure of society, and the state as a superstructural instrument of class rule, countenance Falk's suggestion? How could 'dependencia'- conscious Third World leaders and social activists, many of whom subscribe to Lenin's theory of imperialism (perhaps because it assigns the blame for their condition to outside forces), submit to an increased world role for rapacious MNCs? 
Falk's suggestion that inclusion of World Order education materials in university IR courses might contribute to world order change (an idea supported by Beres and Washburn and Wehr) overlooks much prior research on the implementation-lag experienced by the previous 'new wave' of international studies, behavioralism. Twenty-five years after the onset of the behavioral orientation, collegiate international studies courses still were surprisingly uninfluenced by it. Two surveys indicated that most international studies instructors spent more time teaching "current events," "post-1945 factual detail," and "diagnosis of policy issues," rather than "exposure to../or/ practice in the use of varied analytic techniques and quantitative data" (Rosenau, 1973: 90-101). One of these, a 1974 survey responded to by instructors at 426 campuses, found that 33 percent of the university respondents, 25 percent of the college respondents, and 40 per cent of the junior college respondents answered that they did not expect their students "to be acquainted with or to learn social science methodology" (Grandee, 1974). Falk's target date of world order change by 2000 A.D. is about 25 years beyond the publication of several principal World Order utopian works. What percentage of instructors at that date will respond that they still have not incorporated World Order education into their courses? It may be instructive to note that in 1980, five years after publication of the above major works, an ETS survey of global under standing among American college students found many of them to be chauvinistic, suspicious of world government, and supportive of U.S. military strength.

4. "Identify potential areas of transnational cooperation." What if the intergovernmental cooperation Falk hopes will evolve into a post-state World Polity Association slows down, or even ceases? The scholars who argue that the European integration process has slowed or even come to a standstill are too many to be reviewed here, and certainly too many to be ignored by World Order utopians. Deutsch, et al. concluded long ago after content analysis of the European press that European integration had stagnated, and that loyalty transfer away from the state and toward the community had slowed (Deutsch, 1967: 298). Alker and Puchala (1968: 315), Lindberg and Scheingold (1970), Taylor (1983), and the Royal Institute of International Affairs (The Economist: 16 April 1983: 49) all have arrived independently at similar conclusions about the decreasing momentum of European supranationalism. It seems indisputable that the pace of integration in Europe and in Africa (see below) is not matching the hopes of World Order utopians, while failed integration experiments elsewhere (e.g., the UAR and other attempts at Arab unity) suggest that some regions may await cooperation a long time.

Fruitfulness and Policy Relevance. Another shortcoming is that despite their plea for traditional international studies to emerge from its "theoretical and methodological cocoons" and become more policy-relevant, World Order utopians themselves have not engaged in much substantial research relevant to the formation of a new world order. What follow-up empirical research, or theoretical advances building upon the work of pioneers, have been spawned by any of the WOMP models? Behavioralists once were accused of being insufficiently fruitful and overly concerned with data-making procedures and methodological techniques. World Order utopian modelling suffers a similar affliction: the articles in Beres' and Targ's volume on world order modelling (1975) deal more with the value assumptions, stages, and procedures of developing effective designs than the construction of specific models or the testing of existing World Order models. By the editors' own admission,-the first four essays are "very general discussions of...foundations of inquiry and of proposed modes of analysis...;" a second group of five essays "continues the elaboration of general conceptual weltanschauungen...;" and a third section of five essays "is the most specific with reference to the level of its epistemological/methodological prescriptions and the level of its substantive recommendations," though no world order models are presented (1975: xviii). One 
must ask of the World Order utopians, as one did of the behavioralists, when will they produce policy-relevant scholarship?

\title{
Conceptual Concerns
}

Parsimony. In addition to methodological problems, one may question the World Order utopians' conceptualization of international politics. The scientific mode of investigation demands parsimony; yet World Order utopians have not defined a 'World Order' in relatively parsimonious fashion. One need only compare the early concern of Falk, Galtung, and others with the narrow issue of peace to the present literature's concern with environmentalism, human alienation, social justice, redistribution of wealth, and elimination of conflict to see how broad the definition of a 'World Order' has become. Such an all-encompassing definition forces scholars into sweeping solutions in order to cope simultaneously with mul tiple problems, possibly reducing the chances of achieving any goals. At present, one might subject World Order utopian analysis to the same criticism encountered by the grand theories of Easton (1957) and Snyder (1954); namely, that its framework is too unwieldy. Perhaps until some confirming studies are generated, World Order utopians should aim at developing islands of theory, and the building of bridges between those islands, as behavioralists had to do (McClelland, 1969: 5). If the mul tiple concerns of World Order utopianism were treated as discrete subjects and studied exhaustively, then some of the problems might be solved, and perhaps a 'spillover effect' linking separate but related concerns might occur.

This broad-spectrum definition of 'World Order' perhaps reflects the millenial quality of World Order utopian conceptualizations. One finds millenial thinking in the utopians' assumption of workability, their assumption of the decline of the nationstate, and their assumption that their proposals will assure the values they seek. Basically, these assumptions are anchored in very subjective and arguable conceptualizations of man, the state, war, and change.

Human Nature and Potential. World Order utopians aim not only at restructuring the international system, but also at altering individual perceptions of self and society. Beres, for example, not only hopes that nations might transform their "characteristically egotistic behavior" by "passing through a series of sublimations of national consciousness directed toward a new vision of human community" (1981: 219), but asserts that individuals

\begin{abstract}
...must aim at the realization of the unique and fulfilled Self in harmony with others; an integral vision sparked by an impulse of human singularity. With the manifestation of the One in the Many, each individual may begin to pursue a progressive development of consciousness to ever higher levels of mind.... . The World Order consequences of this synthetic principal may embrace the beginnings of a new community (1981: 140).
\end{abstract}

The difficulty Rousseau found inherent in the establishment of an altruistic society of states may pale in comparison to the difficulties inherent in changing the nature of that curious mixture of cussedness and nobility, the human individual. The sort of human intersubjectivity that Beres hopes for, but has no program for, is a long way off. The premise he and Galtung espouse that world order change can be accomplished by changing human behavior founders on the zeal of some Chinese peasants for recently permitted incremental capitalism, and on the persistence of absenteeism, alcoholism, and black marketeering in Soviet society. Neither Maoism nor Marxism- Leninism has succeeded in remaking human behavior in the image of the "new socialist man," despite the passage of generations and numerous reeducation campaigns against counter-revolutionary tendencies. How are the World 
Order utopians to accomplish with liberal, humanist methods that which has eluded totalitarian rulers armed with official dogmas and the power of the state? This suggests yet another question illuminating a conceptual weakness in the transition thinking of Beres and others who argue that we must transform both states and humans for change to succeed: which comes first? Must attitudinal change precede structural change, or vice versa? Hoffmann frames this problem well when he points out that World Or der utopians do not explain how a citizens' movement espousing global humanism would "overcome national hatreds and prejudices, or the obstacles erected by so many regimes that show no fondness for citizens' movements at all" (1981: 192).

The State's Viability. Yet another conceptual shortcoming has to do with the issue of the viability of the nation-state. In their rush to proclaim the obsolescence of the nation-state, World Order utopians over look that many Third World nations are actively engaged in nation-building at present, and blithely assume that such newlycreated nation-states will be receptive to a post-state world order. They disregard that states still have purpose, such as damping human and social conflict (which has sources deeper than the structure of the state) between tribes, races, or classes of humans; that much of the social and economic justice that now exists is the product of the welfare-state acting in a fiduciary capacity; and that some global order already exists in the operation of diplomacy, alliances, international law, and international organization. World Order utopians, in the search for immediate, guaranteed solutions to all global problems, have failed to imagine that the state system may continue to adapt to changing conditions:

But if we are free to attribute to our imagined alternative form of universal political organization these utopian features, we are also free to think of a state system in which the conditions of a pluralistic security community are generalized (Bull, 1977:285).

The Nature of War. A similar conceptual weakness is apparent in the World Order utopian assumption that their alternative orders will in fact achieve global peace and justice. Certainly, if wars are assumed only to occur between nation-states, then the elimination or controlling of thestate also ends war. However, war is perhaps better conceptualized as organized violence (Corning, 1973: 129). One need only think of pogroms in eastern Europe, or more recently in India, Sri Lanka, Rwanda, and Burundi to conclude that the state is not the cause of all large-scale or chronic violence. Similarly, one need only think of the American and Soviet civil wars to realize that new orders, even idealized ones, do break down. A world order sans nation-states, or comprised of regulated nation-states, is as susceptible to this possibility as any other kind of order. Rebellion and other centrifugal manifestations are always possible (if not likely) in any polity of great area, diverse peoples, and too centralized authority. As Bull puts it:

It is superficial to contend that violent conflict among men is caused by the existence of a system of states without considering whether it does not have deeper causes that would also be operative in any altemative political structure: the availability of violence as a physical option for men in resolving their disputes, and their will to resort to it rather than accept defeat on matters that are vital to them (1977: 284-85).

The Nature of Change. World Order utopians are agreed on the necessity of immediate change (by 2000 A.D.) if the world is to survive impending crisis. When establishing the need for world order change, they often depict the existing system and its actors as intrinsically incapable of meeting these crises, if not in fact the cause of them (Mendlovitz, 1975, Falk, 1975, Washburn and Wehr, 1975a). Yet, when offering their proposed alternatives, they often depict them as new worlds built not on the ashes of the old, but rather by extension of the positive, integrative aspects of the current system while transforming 1) individual attitudes and 2) the interactive behavior of states, (e.g., Galtung says that his own proposed changes do not necessarily "warrant the use of the word revolutionary..."). On the one hand, a case 


\section{The Disnrder of World Order Thought}

is made for fundamental change; on the other hand, radically altered orders are presented to us as adaptations. Perhaps this is because to admit revolution would lessen the prospects for change, or would expose that the "social creators" seek ends that would entail much disruption and destruction.

In truth, most World Order utopian models and educational materials call for such drastic changes at individual, societal, and systemic levels that the elimination of many present institutional arrangements must follow. The transformation of the nation-state and the lessening of ego and self-interest at the individual and societal levels would require, par ticularly among the Center countries, such a radical alteration of standard of living, patterns of behavior, and attitudes that such change might have to be both revolutionary and violent. Indeed, such a possibility is heigh tened by the compressed time-frame in which World Order utopians hope to accomplish the change. According to the Second Law of Thermodynamics, the faster one builds something, the faster entropy occurs. Transition from the existing world order to a different one by 2000 A.D. therefore may not only necessitate violence, but may hasten the pace of the breakdown of the new order.

\section{Empirical Concerns}

As noted, the lack of validating research makes acceptance of World Order utopian prescriptions essentially a leap of faith. There does exist at present a body of quantitative data that casts suspicion on these precriptions. Granted, empiricism in international studies has its shortcomings and shortsightedness; yet, to disregard extant research and recent history while making forecasts or prescribing solutions is to mis take imagination for science.

Basic to some World Order utopian prescriptions is the assumption that increasing transactional flows among both people and states will lead to a decline in stereotypes and tensions producing conflict. While intui tively satisfying, this supposition may not be supported by empirical verification, as Francis Beer's review of existing peace and war research indicates. Beer shows that Rummel's and Russett's respective studies of the relationship between war and trade, Haas' examination of migration, and Naroll, et al.'s study of the linkage between international exchanges and the likelihood of war might be taken to contradict the hypothesis that international transactions conduce peace. Although Beer himself believes such a judgment to be "too harsh", he is nevertheless doubtful about the beneficial aspects of international transactions (1981: 130-36).

Without such confirmation, the assumption that the growing interdependence of a shrinking world is a positive development for peaceful world order is open to question. Perhaps instead, as von Laue notes, the world is not becoming a 'global village,' but a 'global city' -- a nervous, agitated, tense, and hostile web of interdependent interactions that is more atomistic than it is communal. Brzezinski has observed that 'proximity, instead of promoting unity, /may/ give rise to tensions prompted by a new sense of global congestion" (Bull, 1977: 273). Some have argued that the less linkage, the better: in an increasingly transnational, integrated world, it may be more difficult to contain conflict by compartmentalization (Ravenal, 1981: xiv).

Examination of international integration experiences suggests that regional integration does not necessarily stimulate a transnational ethic among the citizens of member states and may, in fact, exacerbate existing tensions, prejudices, and stereotypes. Ziegler (1981: 332) cites de Sola Pool's 1965 study showing that 
foreign travel may bind people more closely to their own country, and other research showing that Arabs working side by side with Israelis displayed increased rather than decreased hostility, as evidence that the result of personal contact may not be immediate accept ance of opposing points of view. To envision integration experiences as leading to world peace "may be expecting too much." To assume that in creased interaction and cooperation will lead to the transcendence of community over the state ignores both history and Huntingdon's argument that predictions of the demise of the nation-state because of increased transactions are

\begin{abstract}
based on a zero-sum assumption about power and sovereignty: that a growth in the power of transnational organizations must be accompanied by a decrease in the power of nation-states. This, however, need not be the case...an increase in number, functions, and scope of transnational organizations will increase the demand for access to national territories and hence also increase the value of the one resource almost exclusively under the control of national governments (Bull, 1977: 272).
\end{abstract}

Illustrating the above is the African integrative experience. Sovereignty, recently won and jealously preserved, has not been subverted by the functional linkages among nations participating in unification efforts. The recent internal conflict over leadership, Chad, and the Polisario which caused the OAU to postpone its annual meeting for over 10 months, reflects the long primacy of political interests over functional linkages, dating back to the early 1960 s when the Brazzaville, Casablanca, and Monrovia groups struggled for supremacy in the OAU. The collapse of the East African Common Market, despite a common language, increasing social and cultural intercourse, an East African Defense Committee, and interrelated educational systems culminating in Makerere College (Mazrui, 1976: 216), is another illustration of the primacy of national interest over functional linkages. Finally, the disintegration of the Desert Locus Control Organization in the aftermath of national rivalry and conflict calls into question the belief that technical cooperation will lead to political cooperation (Ziegler, 1981: 330).

The susceptibility of cooperative linkages to political counterclaims is demonstrated also in the European Economic Community's experience. Granted, a security and economic community exists in Western Europe, yet this has not led to a decline of the nation-state. Recent maneuvering over agricultural policy, Britain's share of the EEC budget, and foreign policy issues suggest that a 'reverse spillover effect $^{\prime}$ is a distinct possibility. A recent Royal Institute of International Affairs report prepared by collaborating think-tanks in London, Bonn, Paris, Rome and The Hague concludes that "If nothing is done, we are faced with the disintegration of the most important European achievement since World War Two." The Economist (1983: 49) adds, "if the EEC is not to disintegrate, its existing policies must be implemented and new order introduced. Like a bicycle, the EEC has to move forward if it is not to tip over."

Obviously, the resistance to unification in Europe and Africa must have a rationale. One obstacle might be selfish parochial interests, which World Order utopians intend to combat through consciousness-raising. But another obstacle which those who advocate both supranational institutions and increased democratic participation (e.g., Galtung, Falk) seem to over look is that significant numbers of people fear such centralization and distance of authority. Successful provincial resistance to certain stronger national powers in the new Canadian constitution, and the political attraction of revenue-sharing and Reagan's devolutionary federalism in the United States suggest that, as Almond and Verba (1963) and others have found, many citizens are leery of strong, distant government even at the national level. The Royal Institute report cited above indicates that grassroots European perceptions of the EEC are similarly unenthusiastic:

On the one hand, national administrators obstruct and delay every stage in community decisionmaking even while they demand more rapid and effective community action. On the other 
hand, the /EEC/is already suffering from the ills which afflict all bureaucracies. Fiefdoms have emerged, catering to their own clienteles; community language has attained heights of obscurity.... The community has become for the peoples of Westem Europe a distant and soulless organization (The Economist, 1983: 49).

Surely these trends suggest that any increase in the remoteness of authority likely will result in increased human alienation.

Just as further integration appears questionable, so the World Order utopian vision of a demilitarized world also appears distant. Falk (1975: 14) and many others subscribe to the 'action-reaction' model of reciprocity, and argue that just as weapons acquisition by one country begets weapons acquisition by another, so American 'no first use" statements and unilateral disarmament moves might lead to reciprocal actions by other powers. However, Rummel (1976: 29-37) finds that cooperation does not buy peace and notes that "Conflict and cooperation are part of a social process...they are therefore related aspects of reaching out and establishing international communication....they are complements." Both he and Nitze (1974) and Wohlsletter (1974a, 1974b) demonstrate that U.S. restraint in the arms race in the 1970 's did not generate reciprocity from the Soviets; rather, they continued to build up their forces.

History contains further confirmation that nations which disarm or stand pat hoping for reciprocity often court aggression. Long before Munich and other examples of the modern era, Carthage literally sued for peace, was disarmed unilaterally, and yet was destroyed by Rome because of continuing economic rivalry. Rivalry creates conflict, and positive signals may not draw a positive response in a world where conflict is a complement of cooperation, and will continue as long as people quarrel over finite resources, power, and status.

Can human behavior change for the better, as Beres and Galtung hope, and alter the security policies of their governments through citizen activism for peace and disarmament? Perhaps, but it may be dangerous to do so unilaterally. Contemporary behavioral experiments using college students as subjects have found that subjects usually attempted to dominate and exploit counterparts who were described to them as ethically-motivated pacifists (Shure, Meeker \& Hansford, 1965). Moreover, informed citizen activism in the West may not be reciprocated by citizens in closed societies in the Communist Bloc. In any event, the citizens of those closed societies may have little need to reciprocate initiatives from the West, as a recent survey of college students in the United States (which Falk, and others term the Center country most crucial to world order change) found that more than 25 percent of the students enrolled as freshmen or junior college students agreed with the statement, "I'm for my country, right or wrong;" almost two-thirds of college students at all levels disagreed with the idea that the U.S. should submit to the authority of a world government; and more than 40 percent at all levels agreed that the U.S. should be stronger than any other nation (ETS 1981: 102-03). Falk, Washburn and Wehr, and others who put their faith in the ability of education to contribute to world order change have their work cut out for them.

\section{Conclusions: The Alchemy of World Order Utopianism}

World Order utopianism claims to attempt a coupling of normative theory and scientific inquiry, in order to transmute international studies from base empiricism into a more noble vehicle for prescription and change. Generally speaking, however, World Order utopian scholarship is quite unscientific, as manifest in its ahistoricism and disregard for existing human knowledge, its loose application of modelling, its challengeable con structions of causation, its questionable prescriptions, its lack of 


\section{Michael A. Kelly and Gary D. Weksin}

policy relevance and fruitfulness, its unparsimonious and arguable conceptualizations, and its disregard for existing quantitative data. We conclude, therefore, that the science ascribed to by World Order utopians is really a 'false science, an alchemy or system of speculative thought aimed at the discovery at panaceas born out of the desire of idealists for a better world.

World Order modellers and educators have avoided some of the stigma attached to traditional utopian scholarship by raising epistemological issues, using behavioral language, and otherwise hewing to the standard of science; still, they have yet to produce much significant research validating existing alternative models and transition strategies, a failing they excuse by trotting out time-worn denunciations of the conservative bias in herent in empirical research.

If the truth be known, however, the attempt to synthesize normative theory and scientific inquiry by the same critics who fault the latter for its conservative bias and irrelevance is quite a compliment to practitioners of the orthodox, empirical approach to international studies. Why would these avowed 'social creators' and 'agents of change,' who seek to alter the basic structure of the world political system, wrap themselves in the cloak of social science, were that cloak not sufficiently respectable to be of some political value to them? In advanced technocratic society, the imprimatur of 'science' or 'expertise' can confer social legitimation upon the claims of political movements such as enviromentalists, right-to-lifers, creationists -- or World Orderists. Social legitimation or respectability is prerequisite to the spread of values and ideas, and is therefore highly desired by the political cadre of such movements, who either seek after endorsements by 'experts,' or seek after credentials themselves.

We are not critical of World Order utopians because we are unsympathetic to their hopes and goals; nor are we crude Realists or positivists. Most of us who practice the orthodox, empirical approach do not study the phenomena of world politics only out of ego or mere scientific curiosity, without any greater purpose in mind. The conservative bias inherent in empiricism certainly may affect one's immediate focus of study, but it need not be taken as representative of one's social vision. Scholars practicing the orthodox approach also desire peace, justice, human dignity, habitability, and freedom from want; but they fail to see how any of these can be achieved merely by wanting them, or through consciousness- raising alone. Problems have causes, and causes must be determined as precisely as possible before relevant, effective, practicable solutions can be sculpted. It is therefore reasonable to predict that as solutions to the above concerns are found, it will be scientific scholars, not classroom visionaries, who find them.

\section{References}

Alker, H. and D. Puchala. (1968). "Trends in Economic Partnership: The North Atlantic Area, 1928-1963," in J.D. Singer (ed.), Quantilative International Politics. New York: Free Press.

Ardrey, R. (1966). The Territorial Imperative. New York: Atheneum.

Beer, F.A. (1981). Peace Against War. San Francisco: W.H. Freeman.

Beres, L.R. (1981). People, States, and World Order. Itasca, IL: Peacock.

Beres, L.R. and H.R. Targ. (1975). Planning Alternative World Futures, New York: Praeger.

Bloomfield, L. and I. (1975). The U.S., Interdependence, and World Order. New York: Foreign Policy Association. 


\section{The Disnrder of World Order Thought}

Bull, H. (1977). The Anarchical Society. New York: Columbia University Press.

Carr, E.H. (1964). The Twenty Years' Crisis. New York: Harper Torchbooks.

Coming, P.A. (1973). "Human Violence: Some Causes and Implications," in C.R. Beitz and T. Herman (eds.), Peace and War. San Francisco: W.H. Freeman, 119-43.

Deutsch, K.W. (1967). France, Germany and the Western Alliance. New York: Charles Scribner's Sons.

Dewey, J. (1923). Outlawry of War: What It Is and Is Not. Chicago: American Committee for the Outlawry of War.

Easton, D. (1957). "An Approach to the Analysis of Political Systems." World Politics, 383-400.

Easton, D. (1969). "The New Revolution in Political Science," American Political Science Review, 63.

The Economist (16 April 1983).

Educational Testing Service. (1981). College Students' Knowledge and Beliefs. New Rochelle: Change Magazine Press.

Falk, R.A. (1972). This Endangered Planet. New York: Vintage Books.

Falk, R.A. (1975). A Study of Future Worlds. New York: Free Press.

Falk, R.A. (1975a). "Toward a New World Order: Modest Methods and Drastic Visions, in S.H. Mendlovitz (ed.) On the Creation of a Just World Order. New York: Free Press, 211-58.

Falk, R.A. (1975b). A Global Approach to National Policy. Cambridge: Harvard University Press.

Fanon, F. (1963). The Wretched of the Earth. New York: Grove Press.

Fox, W.T.R. (1949). "Interwar International Relations Research: The American Experience," World Politics 2, no. 1 .

Galtung, J. (1980). The True Worlds. New York: Free Press.

Grandee, J. (1974). "CLEP: International Relations Survey," Insernational Studies Notes 1: 13-30.

Herz, J.H. (1957). "Rise and Demise of the Territorial State," World Politics, 9.

Hoffman, S. (1981). Duties Beyond Borders. Syracuse: Syracuse University Press.

Hoover, K.R. (1980). The Elements of Social Scientific Thinking. New York: St. Martin's Press.

Kothari, R. (1974). Footsteps into the Future. Delhi: Orient Longman.

Lenin, V.I. (1916). Imperialism: The Highest Stage of Capitalism.

Levinson, S. (1921). Outlawry of War. Chicago: American Committee for the Outlawry of War.

Lindberg, L. and S. Scheingold (1970). Europe's Would-Be Polity. Englewood Cliffs: Prentice-Hall.

Lorenz, K. (1967). On Aggression, trans. by M.K. Wilson. New York: Bantam.

MacIver, R.M. (1964). Social Causation. New York: Harper Torchbook.

de Madariaga, S. (1929). Disarmament. New York: Coward-McCann.

Mazrui, A.A. (1976). A World Federation of Cultures. New York: Free Press.

McClelland, C.A. (1969). "Intemational Relations: Wisdom or Science?" In J.N. Rosenau (ed.), International Politics and Foreign Policy, New York: Free Press.

Mendlovitz, S.H. (1975). On the Creation of a Just World Order. New York: Free Press.

Nachmias, D. and C. Nachmias (1981). Research Methods in the Social Sciences, second edition. 